\title{
Efficacy of Calcium Hydroxylapatite Filler versus Hyaluronic Acid Filler in Hand Augmentation
}

\author{
Wirksamkeit von Calcium-Hydroxylapatit im Vergleich zur \\ injizierbaren Hyaluronsäure bei der Handrückenaugmentation
}

Authors

Institutions
G. Sattler ${ }^{1}$, T. Walker², B. Buxmeyer ${ }^{1}$, B. Biwer ${ }^{2}$

Rosenparkklinik GmbH, Darmstadt, Germany

2 Private practice for skin diseases, allergology and esthetical dermatology, Ludwigshafen, Germany
Bibliography

DOI http://dx.doi.org/

10.1055/s-0034-1378110

Akt Dermatol 2014; 40: 445-451

(c) Georg Thieme Verlag KG

Stuttgart · New York

ISSN 0340-2541

Corresponding author

Dr. med. Gerhard Sattler

Rosenparkklinik $\mathrm{GmbH}$

Heidelberger Landstr. 18-20

64297 Darmstadt

gerhard.sattler@

rosenparkklinik.de

\begin{abstract}
$\nabla$

Purpose: This study compared long-term safety and efficacy of the dermal fillers calcium hydroxylapatite versus hyaluronic acid in hand augmentation in a head-to-head design.

Patients and methods: The partially blinded, randomized study was conducted from July 2012 to November 2013. Subjects aged 45-65 years presenting for hand rejuvenation with a score of 3 or 4 on the validated Merz 5-point hand grading scale were included. Subjects were injected in a randomized manner with calcium hydroxylapatite $\left(\right.$ Radiesse $\left.^{\circledR}\right)$ in the one hand and hyaluronic acid (Juvéderm ${ }^{\circledR}$ Ultra 4 ) in the other hand. Observation time per patient was 12 months. Data were assessed at baseline, week 4-6, and months 3, 9, and 12 . The primary efficacy variable was changes on the hand grading scale. Other assessments included cosmetic result, global esthetic improvement, patient and physician satisfaction, and procedural pain. Adverse events were documented at each follow-up visit.
\end{abstract}

\section{Introduction}

Facial cosmetic procedures to reverse the signs of aging have become widely accepted in the recent decade. However, the face is but one visible manifestation of the aging process. Next to the face, the hands are the most visible unclothed area of the human body. They are continuously subjected to external aging triggers such as sun exposure, meteorological effects and friction forces due to movement [1]. Aging of the hand is characterized by changes in skin texture and volume loss. Alterations in skin texture include irregular surface pigmentation and thinning of the dermis [2]. Volume loss leads to increased exposure of tendons and pronounced veins, causing a bony appearance of the hand [3]. In order to avoid a discrep-
Results: Thirty-seven female patients participated in the study. Both dermal fillers led to significant improvement from baseline on the hand grading scale. 13 patients required a touch-up for both hands, 3 more patients required a touch-up in the hyaluronic acid filler-treated hand only. After 12 months, the treatment effect was still visible for both fillers. The cosmetic result was rated very good or good and global esthetic improvement was concurrently confirmed for both dermal fillers by the blinded and the unblinded physician. There was no difference in terms of satisfaction with the cosmetic result and procedural pain. In total, 11 transient adverse events related to the injection with calcium hydroxylapatite were documented in 6 patients.

Conclusion: Calcium hydroxylapatite and hyaluronic acid are equally suited for achieving longterm results in hand augmentation. Calcium hydroxylapatite was more effective in attaining short-term results with a smaller injection volume. Both dermal fillers were well tolerated and did not induce any serious or unanticipated adverse events.

ancy between a youthful face and aged hands, hand rejuvenation procedures are becoming increasingly requested as a complementary procedure to facial treatments [4].

Due to the increase in demand, a variety of treatment options for hand rejuvenation are available [5]. While textural changes can be addressed by topical agents, dermal fillers have become the treatment of choice for volume restoration [1]. They are non-surgical, easy to administer by experienced physicians and require minimal downtime for the patient [6]. Available options include dermal fillers based on calcium hydroxylapatite and hyaluronic acid.

Radiesse $^{\circledR}$ (Merz Pharmaceuticals GmbH, Frankfurt, Germany) is comprised of calcium hydroxylapatite microspheres suspended in an aqueous 


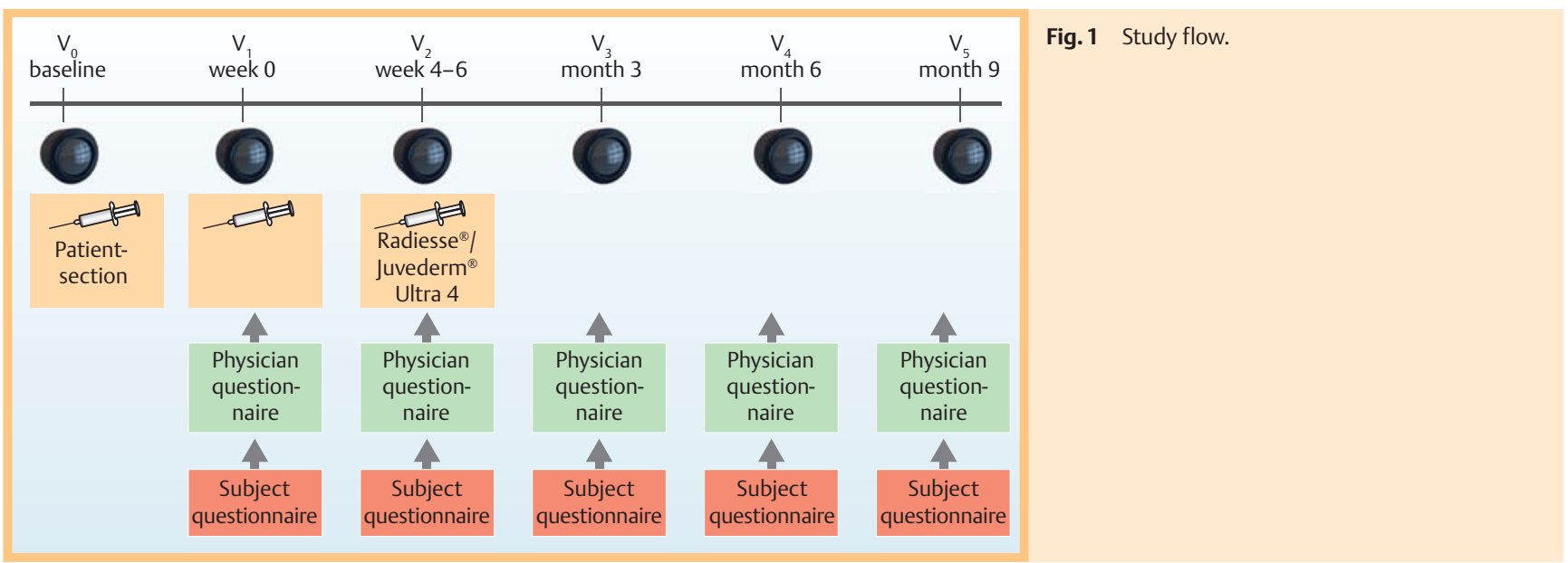

gel carrier. Once injected, it provides immediate volume and correction but continues to work by stimulating the body to produce its own natural collagen. Over time, the gel is absorbed and the body metabolizes the calcium hydroxyapatite microspheres leaving behind only the body's own natural collagen [7].

Juvederm ${ }^{\circledR}$ Ultra 4 (Allergan, Irvine, USA) is a dermal filler composed of non-animal stabilized hyaluronic acid.

Individually, both dermal filler have been studied extensively in terms of safety and efficacy [2,3,6,8-14]. This partially blinded randomized study compared the use of calcium hydroxylapatite versus hyaluronic acid in the hand augmentation for the first time in a head-to-head approach.

\section{Patients and Methods}

$\nabla$

\section{Study Design}

The long-term efficacy and safety of calcium hydroxylapatite versus hyaluronic acid in hand augmentation was compared headto-head in a partially blinded, randomized study conducted at two German centers from July 2012 to November 2013. Observation time per patient was approximately 12 months. Data were assessed at baseline, week 4-6, month 3 , month 9 , and month 12 Fig. 1). Patients were free to withdraw from the study at any time and for any reason. This partially-blinded, comparative, randomized, prospective clinical study was performed in line with national and international regulations. All participants provided their written informed consent prior to entering the study.

\section{Participants}

Subjects aged $45-65$ years with severe or very severe loss of fatty tissue with moderate or marked prominence of underlying veins and tendons equivalent to a score of 3 or 4 according to the validated Merz 5-point hand grading scale [15] presenting for hand rejuvenation were included in the study. Exclusion criteria included allergy/incompatibility to one of the ingredients, previous injections of degradable fillers within the last 9 months, and previous injections of permanent fillers.

\section{Treatment}

Subjects were injected in a randomized manner with calcium hydroxylapatite (Radiesse ${ }^{\circledR}$ ) in the one hand and hyaluronic acid (Juvéderm ${ }^{\circledR}$ Ultra 4 ) in the other hand. Use of local anesthetics was subject to the physician's discretion. Calcium hydroxylapatite was injected with a 27 gauge ID cannula and hyaluronic acid was injected using the injection device identified in the approval product labeling (27G $1 / 2$ '). If the physician was familiar with blunt cannulae ( $25 \mathrm{G} 38 \mathrm{~mm}$ ), this was eligible as well. A prerequisite was, however, that both hands were treated with the same technique and the same amount of material $(0.8 \mathrm{~mL})$ at baseline. In addition, both products had to be used according to the labeled instructions including all stated precautions and warnings. Injection technique was chosen according to the physician's regular use. Recommended injection technique was tenting and injection at an angle of $45^{\circ}$ of $3-4$ small boli of approximately $0.1-0.2 \mathrm{~mL}$ each interdigitally. After injection, the physician was advised to massage the filler thoroughly into the patient's loose-fisted hand to evenly distribute the material and achieve the desired cosmetic result. Patients were informed not to do heavy handwork (e.g. computer work, bearing of heavy boxes etc.) for at least 5 days, to elevate hands as much as possible at the heartlevel and to rest hands at night on a pillow in order to prevent excessive swelling. Optional touch-up was performed 4-6 weeks after baseline until optimal esthetic outcome was achieved. Retreatment was offered to patients at the end of the study (12 months after baseline).

\section{Assessment}

Prior to treatment, the subjects had photographs of their hands taken. These photos were used by the physician to later assess the effect of treatment (blinded rating). A live rating was conducted before and immediately after the treatment. Subjects were scheduled to return approximately 4-6 weeks, 3, 9, and 12 months after first treatment for an assessment of their hands. Follow-up photographs were taken as described before. The primary efficacy variable was changes on the hand grading scale ( $0=$ no loss of fatty tissue, $1=$ mild loss of fatty tissue; slight visibility of veins, 2 = moderate loss of fatty tissue; mild visibility of veins and tendons, $3=$ severe loss of fatty tissue, moderate visibility of veins and tendons, 4 = very severe loss of fatty tissue, marked visibility of veins and tendons) as assessed by the investigator. At each visit, the current cosmetic result in comparison to pre-treatment conditions at baseline was assessed by the patient using a 9 -point rating scale $(+4=$ complete improvement, $+3=$ marked improvement, $+2=$ moderate improvement, $+1=$ slight improvement, $0=$ no change, $-1=$ slight worsening, $-2=$ moderate worsening, -3 = marked worsening, $-4=$ very marked worsening). 
Physicians rated the cosmetic result on a 5-point Likert scale ( $1=$ very good, 2 =good, $3=$ fair, $4=$ poor, $5=$ very poor). In addition, changes compared to baseline photos were rated on the Global Aesthetic Improvement Scale $(1=$ very much improved, $2=$ much improved, $3=$ improved, $4=$ no change, $5=$ worse) [16] by the investigator, a blinded physician and the subject. Satisfaction with the effects of the treatment for both hands separately in comparison to pre-treatment conditions at baseline was rated by the investigator, a blinded rater and the patient on the 5-point Likert scale (very satisfied, satisfied, indifferent, dissatisfied, very dissatisfied). Subjects were also asked about satisfaction with their treatment and their quality of life as well as their preference regarding each hand/product used, recommendation and likeliness to return for further treatments. After each treatment, pain was assessed on a visual analog scale $(0=$ no pain, $10=$ worst imaginable pain). Adverse events were documented at each follow-up visit. Overall safety was rated by the physician on a 5 -point Likert scale ( 1 =very good, 2 = good, $3=$ fair, 4 = poor, 5 = very poor $)$.

\section{Statistical Analyses}

All data analyses were carried out according to a pre-established analysis plan. The collected data were analyzed with epidemiological methods, using the SPSS for Windows program package (Version 15.0). For continuous variables, statistic parameters including arithmetic mean, standard deviation and range were calculated. Frequency distributions for discrete variables were provided as percentage in relation to the total sample. Free text answers were transferred post hoc into adequate coding schemes and analyzed as frequency distribution. Evaluation of parameters measuring the clinical course were performed by intraindividual difference analysis (first vs. last examination) using the Wilcoxon signed-rank test. Difference was calculated per patient and subsequently averaged. Patients with missing data for one or both variables were not imputed. All tests were two-sided, and significance was declared at the 0.05 level.

\section{Results \\ $\nabla$}

\section{Baseline Characteristics and Administration}

In total, 37 female patients (median age 56 years, range $45-65$ ) were enrolled from 2 centers. At baseline, the majority of patients (59.5\%) had severe loss of fatty tissue and moderate visibility of veins and tendons equivalent to grade 3 on the hand grading scale. There was no difference between right and left hand grading at baseline. In all patients, the injections were administered using the Fanning technique. During the initial injection, both hands were treated with the same amount of material.

\section{Efficacy}

Compared to baseline, both dermal fillers led to significant improvement on the hand grading scale ( $\bullet$ Fig. 2). After 4-6 weeks, mean improvement was significantly more pronounced with calcium hydroxylapatite $(1.3 \pm 0.7$ vs $1.1 \pm 0.5, \mathrm{p}=0.0253)$. Sixteen patients (43.2\%) required a touch-up after $4-6$ weeks in order to optimize the result. Thereby, calcium hydroxylapatite was administered in 4 patients per 3 injections à $0.8 \mathrm{~mL}$ in area 1 and in 9 patients per 1 injection à $0.13 \mathrm{~mL}$ in areas $1-6$, whereas hyaluronic acid was administered in 6 patients per 3 injections à $0.8 \mathrm{~mL}$ in area 1 and in 10 patients per 1 injection à $0.13 \mathrm{~mL}$ in areas $1-6$. This led to further improvement. In 3 patients, the touch-up was necessary only in the hand that had been treated



Fig. 2 Changes on the validated hand grading scale after injection.

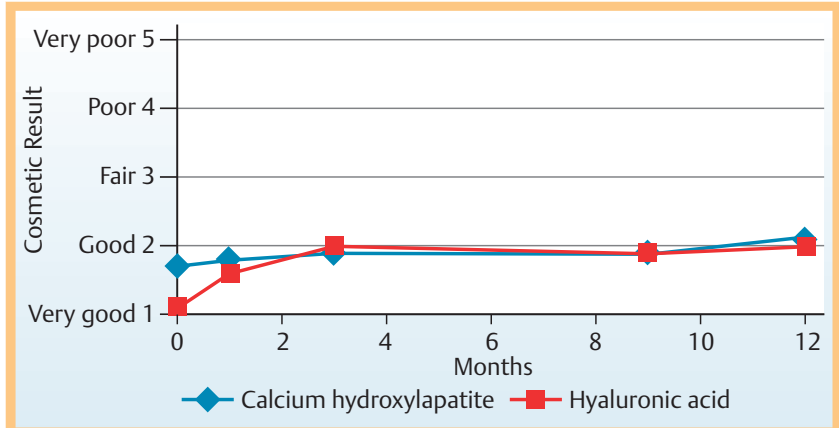

Fig. 3 Cosmetic result over the course of the study.

with hyaluronic acid. After 12 months, the treatment effect was still visible for both fillers, albeit not as pronounced. The difference between calcium hydroxylapatite and hyaluronic acid was no longer significant at this point of time.

The cosmetic result was rated very good or good for both dermal fillers ( $\bullet$ Fig.3). Immediately after initial injection the cosmetic result was rated significantly better for hyaluronic acid compared to calcium hydroxylapatite $(1.1 \pm 0.3$ vs $1.7 \pm 0.5, p=0.0023)$. Over the course of the study, the cosmetic result diminished slightly for both fillers, whereby the deterioration was more pronounced in the hands treated with hyaluronic acid. From month 1 through 12 , there was no difference in the cosmetic result between both methods. Yet, the cosmetic result was still rated as "good" for both hands after 1 year ( $\bullet$ Fig. 4 ).

Based on the photo documentation, the global esthetic improvement was concurrently confirmed for both dermal fillers by the blinded and the unblinded physician ( $\bullet$ Fig.5). The observed improvement diminished slightly over the course of the study. A difference between the filler methods was apparent after the initial injection. In this instance, improvement with calcium hydroxylapatite was rated as more pronounced compared to hyaluronic acid. Rating by the patient showed the same trend as the physicians' assessment, although no difference between the fillers was noticed by the patient. Consistently, no differences between calcium hydroxylapatite and hyaluronic acid were observed in the patients' global assessment ( $\bullet$ Fig. $\mathbf{6}$ ). Improvement diminished profoundly with both fillers over the course of the study.

The satisfaction of physicians - blinded and unblinded - as well as patients with the cosmetic result was equally high for both dermal fillers. Immediately after the injection, the degree of 



Fig. 4 Photo documentation of cosmetic result (female patient 52 years, treated with Radiesse ${ }^{\circledR}$ in her right hand and Juvéderm ${ }^{\circledR}$ Ultra 4 in her left hand: a before treatment, $\mathbf{b}$ immediately after injection, $\mathbf{c} 12$ months after injection).

satisfaction with the cosmetic result was rated concurrently for the majority of patients as satisfied or very satisfied. In line with the diminishing effect, the satisfaction lessened over the course of the study, but remained on the level of "satisfied" for the majority of patients. No difference was observed between calcium hydroxylapatite and hyaluronic acid in terms of satisfaction with the result. In accordance with these data, patients felt more attractive and had increased emotional well-being after the treatment. The majority of patients stated that they would return for another treatment.

\section{Safety}

The pain experienced during the injection was comparable for both dermal fillers. Patients rated the pain either as very mild or non-existent. Mean pain assessment on the visual analog scale ( 0 -100) was $8.8 \pm 9.8$ for calcium hydroxylapatite and $7.7 \pm 8.4$ for hyaluronic acid $(\mathrm{p}=0.5865)$.

In total, 11 adverse events were documented in 6 patients. All adverse events were related to the injection with calcium hydroxylapatite. The most frequent adverse event occurring at the injection site was edema $(n=4)$, followed by pain $(n=3)$ and impaired movement $(n=2)$. Other treatment-related adverse events were loss of sensitivity and touch-sensitivity. Adverse events usually resolved without intervention within 2 weeks. No serious adverse events were reported during the course of the study. Ten patients were lost to follow-up after a median duration of 93 days (range $1-457$ ). The overall safety of both dermal fillers was assessed as good or very good by the investigator ( Fig. 7). Due to the occurrence of adverse events related to calcium hydroxylapatite, slight differences in favor of hyaluronic acid were documented at month 1 and 3.

\section{Discussion}

$\nabla$

The present non-interventional study evaluated the long-term efficacy and safety of calcium hydroxylapatite versus hyaluronic acid in hand augmentation. Both dermal fillers were comparable in achieving satisfactory long-term cosmetic results. Short-term effects tended to be more pronounced in the hand treated with calcium hydroxylapatite although both hands had initially received the same amount of material. In consistence with this observation, a touch-up was required more often with hyaluronic acid in order to achieve comparable results. Accordingly, a headto-head comparison during the follow-up visits has to be interpreted with this borne in mind. The difference in the total volume required to achieve satisfactory hand augmentation is a consequence of the physicochemical characteristics of both fillers. Compared to hyaluronic acid, calcium hydroxylapatite has a markedly higher viscosity and elasticity $[17,18]$. High viscosity provides the advantage that the filler will tend to remain at the injection site with minimal migration, which allows precise sculpturing. High elasticity confers the benefit of resistance to applied forces from musculature or gravity. Split-face study data have shown that calcium hydroxylapatite required a smaller volume for optimal nasolabial fold correction than that required when hyaluronic acid was used $[19,20]$. Our observation confirmed that these differences in rheological properties between both fillers are also relevant in hand augmentation.

Filler longevity is of significant concern to patients. Individually, the long-term efficacy of hyaluronic acid [21] and calcium hydroxylapatite $[2,6,22]$ has been shown in previous studies. To the best of our knowledge, this was the first head-to-head comparison of calcium hydroxylapatite and hyaluronic acid in the application for hand augmentation.

The long-lasting effect of calcium hydroxylapatite has been ascribed to neocollagenesis [23]. Immediately after injection, the soluble carrier gel evenly distributes the calcium hydroxylapatite microspheres. The interstitial space between the microspheres is initially filled by the carrier gel, which dissipates gradually [24], leaving the calcium hydroxylapatite microspheres at the injection site where they induce collagenesis $[7,25,26]$. This keeps the microspheres anchored at the injection site, whereby trans- 




Fig. 5 Global esthetic improvement rated by the unblinded physician.

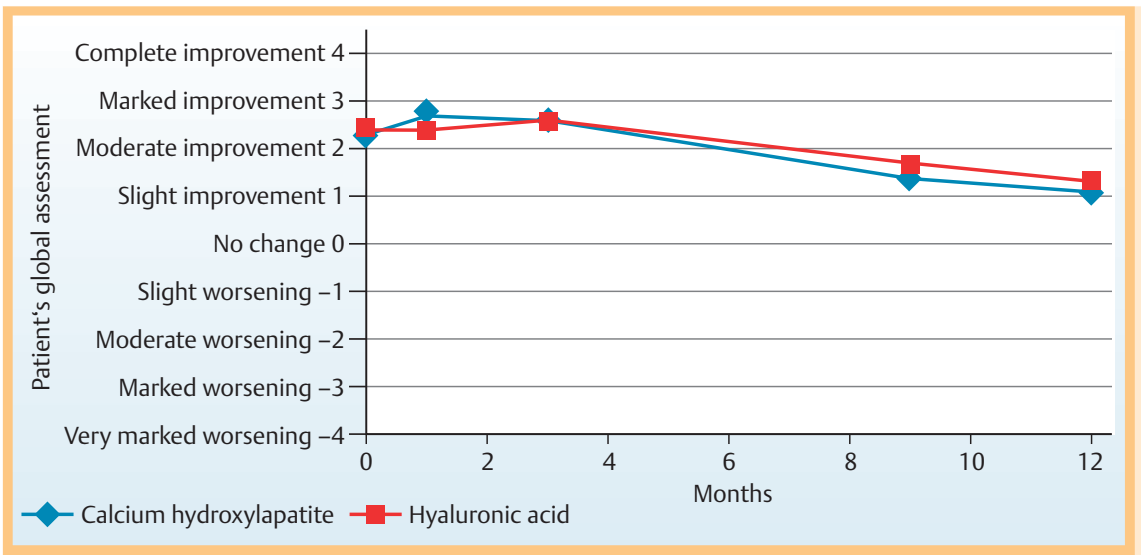

Fig. 6 Patients' global assessment over the course of the study.

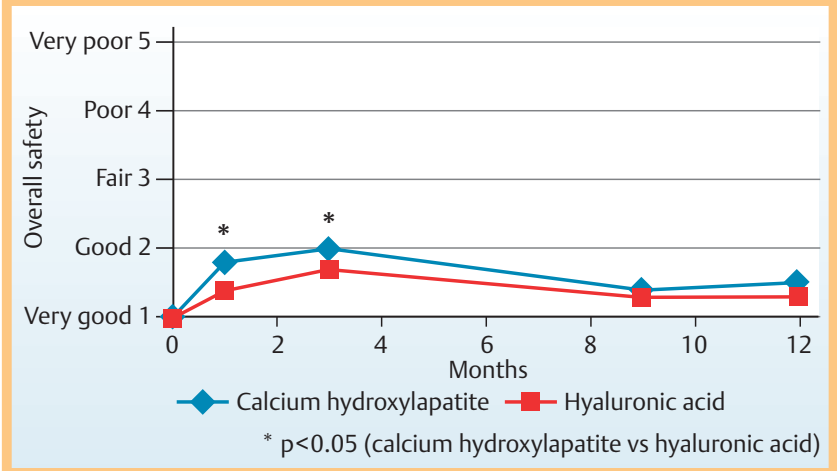

Fig. 7 Overall safety assessed by the investigator.

location of calcium hydroxylapatite is effectively prevented and long-lasting results are ensured. An average duration of effect of 15 months has been reported for calcium hydroxylapatite in the treatment of nasolabial folds, and in some cases even longer than 30 months [27]. Our study confirmed the longevity of both dermal fillers in the application of hand augmentation: after one year, the mean cosmetic result was still rated as good.

Due to its identical composition to the calcium hydroxylapatite mineral compound found in human bone, this filler has been produced synthetically and is therefore highly biocompatible and bears only a low risk of provoking immune responses $[4,28]$. As expected, no inflammatory reactions were reported in our study and the small number of adverse events related to calcium hydroxylapatite was usually transient and resolved without intervention. Edema lasting for 1-10 days after the injection of calcium hydroxylapatite is a known post-procedural adverse event that occurs due to the higher lifting capacity attributed to calcium hydroxylapatite in comparison to hyaluronic acid [4]. In order to minimize edema, patients are instructed to keep their hands elevated for the first 24 hours after the procedure. Thus, the occurrence of edema might be a result of the patient refraining from following this advice. Accordingly, physicians rated the overall safety of both dermal fillers as good or very good.

The good safety and efficacy profile attested in this study led to a high degree of patient satisfaction, which corresponds well with previous observations [2,3]. Despite the adverse events related to the injection and high elasticity of calcium hydroxylapatite patients were willing to return for an encore treatment.

The study is limited by the small patient number. However, the involvement of a blinded rater to avoid bias ensures the robustness of the data presented here.

\section{Conclusion \\ $\nabla$}

A head-to-head comparison of calcium hydroxylapatite and hyaluronic acid showed similar long-term efficacy in hand augmentation, whereby calcium hydroxylapatite was more effective in achieving short-term results with a smaller volume. Both dermal fillers were well tolerated and did not induce any serious or unanticipated adverse events.

\section{Conflict of interest \\ $\nabla$}

G. Sattler is a member of the Merz Advisory Board and has received an event related honorarium. He also participated in several scientific trials as a principle investigator and he received com- 
pensation for conducting the study in his research center. T. Walker received in the past honorarium for lectures, actually he is part time employee at Merz Pharmaceuticals. B. Buxmeyer and B. Biwer have nothing to declare.

\section{Zusammenfassung}

\section{Wirksamkeit von Calcium-Hydroxylapatit im Vergleich zur injizierbaren Hyaluronsäure bei der Handrücken- augmentation}

Ziel: Diese Studie vergleicht die Langzeit-Sicherheit und die Effektivität einer Behandlung mit einem dermalen Calcium-Hydroxylapatit-Filler gegenüber einem Hyaluronsäure-Filler im Rahmen einer Hand-Augmentation unter Verwendung eines 1-zu-1-Designs.

Patienten und Methoden: Die teilweise verblendete, randomisierte Studie wurde von Juli 2012 bis November 2013 durchgeführt. Die in die Studie eingeschlossenen Patienten waren zwischen 45-65 Jahren alt und hatten einen Behandlungswunsch zur Handverjüngung mit einem Grad 3 oder 4 auf der validierten Merz 5-Punkte-Hand-Skala. Die Patienten wurden in einer randomisierten Art in die Studie aufgenommen und mittels Injektion mit Calcium-Hydroxylapatit an einer Hand und an der kontralateralen Hand mit Juvéderm ${ }^{\circledR}$ Ultra 4 behandelt. Der Beobachtungszeitraum pro Patient betrug 12 Monate. Die Befunde wurden zu Beginn der Studie, nach 4 bis 6 Wochen und nach 3, 9, und 12 Monaten erhoben. Dier primäre Wirksamkeitsgrad wurde aufgrund von einer Änderung der 5-Punkte-Merz-Hand-Skala bestimmt. Andere Beobachtungen beinhalteten das ästhetische Behandlungsergebnis, die allgemeine ästhetische Verbesserung sowie die allgemeine Zufriedenheit des Behandlers und des Patienten und die Frage des Behandlungsschmerzes. Unerwünschte Nebenwirkungen wurden bei jedem Follow-up-Besuch dokumentiert.

Ergebnisse: 37 weibliche Patienten haben an der Studie teilgenommen. Beide dermalen Filler führten zu einer signifikanten Verbesserung gegenüber dem Ausgangbefund auf der Merz 5Punkte-Graduierungsskala. 13 Patienten benötigten eine „touchup-Behandlung für beide Hände“, 3 weitere Patienten benötigten eine touch-up-Behandlung nur auf der Hyaluronsäure-Seite. Nach 12 Monaten war der Behandlungseffekt auf beiden Seiten noch sichtbar. Der kosmetische Effekt wurde als gut oder sehr gut beurteilt und die ästhetische Verbesserung wurde für beide dermalen Filler bestätigt durch den verblindeten und den nicht verblindeten ärztlichen Therapeuten. Es gab keine Unterschiede hinsichtlich der Zufriedenheit oder der Schmerzen während der Behandlung. Insgesamt wurden 11 vorübergehende Nebenwirkungen bei 6 Patienten beobachtet, die mit der Injektion von Calcium-Hydroxylapatit in Bezug standen.

Schlussfolgerung: Calcium-Hydroxylapatit und Hyaluronsäure sind in gleichem Maße geeignet, um dauerhafte Ergebnisse bei der Hand-Augmentation zu erzielen. Calcium-Hydroxylapatit war effektiver in der Kurzzeitanwendung bei der Verwendung von kleineren Volumina. Beide dermalen Filler wurden sehr gut toleriert und haben keine schweren oder unerwarteten Nebenwirkungen gezeigt.

\section{Acknowledgements}

$\nabla$

The authors would like to thank Dr. P. Jöstingmeyer (med:unit $\mathrm{GmbH}$, Cologne, Germany) for editorial assistance and Merz Pharmaceuticals GmbH (Frankfurt, Germany) for material support and funding the publication.

\section{References}

1 Kühne $U$, Imhof $M$. Treatment of the ageing hand with dermal fillers. J Cutan Aesthet Surg 2012; 5: 163 -169

2 Marmur ES, Al Quran H, De Sa Earp AP et al. A five-patient satisfaction pilot study of calcium hydroxylapatite injection for treatment of aging hands. Dermatol Surg 2009; 35: 1978 -1984

3 Busso M, Moers-Carpi M, Storck R et al. Multicenter, randomized trial assessing the effectiveness and safety of calcium hydroxylapatite for hand rejuvenation. Dermatol Surg 2010; 36: 790 - 797

4 Fabi SG, Goldman MP. Hand rejuvenation: a review and our experience. Dermatol Surg 2012; 38: 1112-1127

5 Nijhawan RI, Rossi AM, Perez MA. Soft Tissue Augmentation, Part 2: Hand Rejuvenation. Cosmet Dermatol 2012; 25: 351 - 355

6 Sadick NS. A 52-week study of safety and efficacy of calcium hydroxylapatite for rejuvenation of the aging hand. J Drugs Dermatol 2011; 10: 47-51

7 Berlin AL, Hussain M, Goldberg DJ. Calcium hydroxylapatite filler for facial rejuvenation: a histologic and immunohistochemical analysis. Dermatol Surg 2008; 34 (Suppl. 01): 64-67

8 Haq S, Storck R, Baspeyras M et al. Multinational, multipatient study of calcium hydroxylapatite for treatment of the aging hand: European Cosmetic Physician Group on hand augmentation. Dermatol Surg 2010; 36: $782-789$

9 Pavicic T. Calcium hydroxylapatite filler: an overview of safety and tolerability. J Drugs Dermatol 2013; 12: 996-1002

10 Bank DE. A novel approach to treatment of the aging hand with Radiesse. J Drugs Dermatol 2009; 8: 1122-1126

11 Smith SR, Jones D, Thomas JA et al. Duration of wrinkle correction following repeat treatment with Juvéderm hyaluronic acid fillers. Arch Dermatol Res 2010; 302: 757-762

12 Man J, Rao J, Goldman M. A double-blind, comparative study of nonanimal-stabilized hyaluronic acid versus human collagen for tissue augmentation of the dorsal hands. Dermatol Surg 2008; 34: 1026-1031

13 Brandt FS, Cazzaniga A, Strangman $N$ et al. Long-term effectiveness and safety of small gel particle hyaluronic acid for hand rejuvenation. Dermatol Surg 2012; 38: 1128-1135

14 Hartmann V, Bachmann F, Plaschke $M$ et al. Hand augmentation with stabilized hyaluronic acid (Macrolane VRF20 and Restylane Vital, Restylane Vital Light). J Dtsch Dermatol Ges 2010; 8: 41-44

15 Carruthers A, Carruthers J, Hardas B et al. A Validated Hand Grading Scale. Dermatol Surg 2008; 34: S179-S183

16 Narins RS, Brandt F, Leyden J et al. A randomized, double-blind, multicenter comparison of the efficacy and tolerability of Restylane versus Zyplast for the correction of nasolabial folds. Dermatol Surg 2003; 29: 588-595

17 Sundaram H, Voigts B, Beer K et al. Comparison of the rheological properties of viscosity and elasticity in two categories of soft tissue fillers: calcium hydroxylapatite and hyaluronic acid. Dermatol Surg 2010; 36 (Suppl. 03): 1859-1865

18 Sundaram H, Cassuto D. Biophysical characteristics of hyaluronic acid soft-tissue fillers and their relevance to aesthetic applications. Plast Reconstr Surg 2013; 132: 5S-21S

19 Moers-Carpi M, Vogt S, Santos BM et al. A multicenter, randomized trial comparing calcium hydroxylapatite to two hyaluronic acids for treatment of nasolabial folds. Dermatol Surg 2007; 33 (Suppl. 02): 144-151

20 Moers-Carpi MM, Tufet JO. Calcium hydroxylapatite versus nonanimal stabilized hyaluronic acid for the correction of nasolabial folds: a 12month, multicenter, prospective, randomized, controlled, split-face trial. Dermatol Surg 2008; 34: 210-215

21 Prager W, Wissmueller E, Havermann I et al. A prospective, split-face, randomized, comparative study of safety and 12-month longevity of three formulations of hyaluronic acid dermal filler for treatment of nasolabial folds. Dermatol Surg 2012; 38: 1143 - 1150

22 Jansen DA, Graivier MH. Evaluation of a calcium hydroxylapatite-based implant (Radiesse) for facial soft-tissue augmentation. Plast Reconstr Surg 2006; 118 (Suppl. 03): 22S-30S, discussion 31S-33S 
23 Edelson $K L$. Hand recontouring with calcium hydroxylapatite (Radiesse). J Cosmet Dermatol 2009; 8: 44-51

24 Mayer $R$, Lightfoot $M$, Jung I. Preliminary evaluation of calcium hydroxylapatite as a transurethral bulking agent for stress urinary incontinence. Urology 2001; 57: 434-438

25 Coleman KM, Voigts R, DeVore DP et al. Neocollagenesis after injection of calcium hydroxylapatite composition in a canine model. Dermatol Surg 2008; 34 (Suppl. 01): S53-S55
26 Marmur ES, Phelps R, Goldberg DJ. Clinical, histologic and electron microscopic findings after injection of a calcium hydroxylapatite filler. J Cosmet Laser Ther 2004; 6: 223 -226

27 Bass LS, Smith S, Busso M et al. Calcium hydroxylapatite (Radiesse) for treatment of nasolabial folds: long-term safety and efficacy results. Aesthet Surg J 2010; 30: 235-238

28 Pavicic T. Calcium hydroxylapatite filler: an overview of safety and tolerability. J Drugs Dermatol 2013; 12: 996-1002 